\title{
ONLINE EFL TEACHING DURING THE COVID-19 CRISIS: CHANGES IN TRAINEE-TEACHERS' PLANNING AND TEACHING APPROACHES
}

\author{
Irina Ivanova \\ Department of English Studies, \\ Konstantin Preslavsky University of Shumen, Bulgaria
}

\begin{abstract}
The article deals with the changes in planning and conducting EFL lessons which resulted from the transition to online teaching due to the Covid-19 pandemic. The data on which the present discussion is based were obtained from three sources: lesson plans prepared by trainee-teachers' (both novice and already practicing) enrolled in an MA course in a Bulgarian state university, oral discussions of the same lesson plans between the trainees and the university supervisor, and video clips of lessons recorded by trainees who at the time of the study worked as teachers in schools. The analysis showed that there were a number of changes in planning for online teaching, and these changes were duly reflected in the teaching the lessons, the evidence of which can be found in the videos submitted together with the plans. The changes in the teaching approach, classroom management and the use of teaching materials were made by the trainees in an attempt to adjust their approach to the modifications of the online learning environment. The analysis helped us identify some features of online teaching which shed light on the processes of adjustment the trainees went through, and the way this transition affected the nature of their teaching. Some of the most symptomatic changes involved increased teacher-centredness in both planning and teaching, and preference for deductive approaches in presenting grammar and vocabulary, which resulted in fewer opportunities for students' active involvement and participation in the lesson.
\end{abstract}

Keywords: online teaching, lesson planning, trainee-teachers, change, Covid 19

\begin{abstract}
About the author: Associate Professor Irina Ivanova, PhD, is a lecturer in ELT Methodology at the Department of English studies, Konstantin Preslavsky University of Shumen, Bulgaria. She has expertise and extensive experience in pre-and in-service teacher training and supervision, and is involved in teacher certification and professional development. Her research interests and publications are in the area of ELT, teacher training and continuous professional development, academic literacy, assessment and quality assurance.
\end{abstract}

e-mail: irina.ivanova@shu.bg

ORCID iD: https://orcid.org/0000-0002-0216-7061

Copyright (C) 2021 Irina Ivanova

Article history: Received: 30 June 2021; Reviewed: 18 August 2021; Revised: 20 August 2021; Accepted: 22 August 2021; Published: 31 August 2021

This open access article is published and distributed under a Creative Commons Attribution 4.0 International License.

Citation (APA): Ivanova, I. (2021). Online EFL teaching during the covid-19 crisis: changes in traineeteachers' planning and teaching approaches. Studies in Linguistics, Culture, and FLT, 9(2), 51-63. https:// doi.org/10.46687/FCUV7641 


\section{Introduction}

The present Covid-19 crisis and the way it affected and changed our lives makes the following Alvin Toffler's quote from the 70s strikingly relevant: "Change is the process by which the future invades our lives, and it is important to look at it closely, not merely from the grand perspectives of history, but also from the vantage point of the living, breathing individuals who experience it" (Toffler, 1970, p.10). The enormity of the change and the short period within which it happened caused unprecedented reverberations in all areas of social life, including education.

Since the beginning of the Covid-19 pandemic most teacher-training institutions worldwide have created their own or adapted existing online platforms in order to maintain the teacher preparation process and respond to a growing demand for specialists who are prepared for the changed reality of online education. In the context of general unpredictability and hastily introduced changes brought about by the pandemic, a lot of practicing teachers found themselves incapable of continuing teaching in the way they were accustomed to, or were temporarily forced to leave teaching due to illness or quarantine. These circumstances created an urgent need for both new or substitute teachers, and even teachers who had not completed their formal education, to become part of schools' regular staff, some of them without having done their internship or having worked with a more experienced mentor. As a result, a lot of trainees had to combine their studies towards a teaching qualification with work as regular teachers in schools. This necessitated a quick adaptation to the condition of online teaching and an urgent need to learn new skills of working with technology and planning and teaching entirely online. Unfortunately, most of the universities were equally unprepared for this transition and had to respond by changing the way of instruction at the same time as the teachers in schools, so the trainees had not received training and advice for teaching online either at university or in their schools (if they worked in a school) and had to experiment and learn on the go. Therefore, the changes they made to their planning and teaching are worth researching as they might lead to identifying some deficiencies and potential remedies that work in the present situation.

\section{Theoretical background}

Over the last year Covid-19 crisis and its consequences for education have dominated research in an unprecedented way. A large number of studies in a wide variety of areas appeared in an attempt to reflect and make sense of the rapid changes in the teaching approaches and learning patterns in different educational contexts. The already existing research in online education and distance learning had to be revisited and its implications and recommendations adapted, as this form of teaching and learning became the only possible option 
in the present circumstances. Before the pandemic, purely online instruction served as a replacement for face-to-face teaching, as it was seen as an attractive alternative for both cost reasons and in terms of student outcomes, as opposed to blended learning which was supposed to offer an enhancement of face-face instruction (Means et al, 2013). However, since March 2020 online teaching has become the only possible option for educational institutions worldwide.

The most obvious type of change, which resulted from the initial shock of school closures early in 2020, was teachers' transition to online teaching with all its challenges, including first and foremost acquiring digital competence and adoption of fully online teaching. In a study of early career teachers' adaptation to online teaching, Konig et al. (2020) showed that countries which had already started to implement a strategy requiring schools to foster digital competences had better chances for a quick transition to online education. Thus, in Germany just before the lockdown, $98 \%$ of all teachers used digital communication media in their work outside teaching. This ensured confidence and high self-efficacy in teaching online, closely linked to possessing 'technological pedagogical knowledge', i.e. professional knowledge about technologies for application in teaching and learning situations that are not bound to a specific subject (ibid, p. 4). However, good digital competences alone are not enough for quality instruction. Research has put forward a core of important features of online education such as student-centered teaching, collaborative, problem-based learning, small-group work, and authentic performance-based assessment (see Lowes, 2008), which require special attention in preparing teachers for working in a virtual environment.

Another factor which appears to affect successful transition to online teaching is so-called faculty readiness, the extent to which the teaching staff at an institution is prepared to implement online teaching, taking into consideration the affective and cultural aspects of such a transition (Cutri et al, 2020). Previous research identified teacher educators' lack of confidence and competence in the transition to online teaching before the Covid-19 crisis (Downing \& Dyment, 2013; Dyment \& Downing, 2018). Therefore, educational institutions which offer online teaching, such as Virtual High School (VHS) - the oldest U.S. provider of distance learning courses - make sure that all their teachers undergo systematic and easily accessible training which allows them "to bring good pedagogy to online environment" (Lowes, 2008, p. 3). In this respect, universities which offered distance learning, both synchronous and asynchronous, had a great advantage over institutions which didn't offer this type of instruction. Indeed, as Scull et al. (2020, p. 502) point out, "simply because students have grown up with increasingly ubiquitous and advanced digital technologies does not mean that they naturally know how to study in online spaces". 
It would be useful to look into research which discusses the ways in which online teaching before the pandemic might have beneficial effects on face-toface teaching. There are a lot of already existing teaching paradigms which show how online teaching can be used to enrich traditional classroom practice by enhancing students' engagement, their reflective thinking and communication. One such example is the Community of Inquiry framework whose practices are "grounded in cognitive presence, social presence and teaching presence, which enable the creation of a cohesive community of learners" (Garrison et al., 2010 cited in Warner 2016, p. 4). Roblyer et al. (2009) also write about the 'reverse impact phenomenon', summarizing research on the way virtual teaching experiences have a positive impact on face-to-face teaching practices, in the methods for presenting the content, in the social dynamics - the effective ways of facilitating online discussions and student engagement, and in assessment strategies, including formative feedback from the teacher. Their findings reveal three types of impact: increased technology use and integration instruction, more effective teaching strategies, and better communication and empathy with students.

However, some recent research findings point to a shift in the traditional concepts of preparation and readiness and the creation of a new temporality which renders the longitudinal perception of a thorough preliminary preparation almost irrelevant. The imposed closure due to Covid-19 has indeed been "a trigger for educational institutions worldwide to pursue creative approaches in a relatively short notice" (Muthuprasad et al., 2021, p. 1). In these circumstances the role of teachers' competence, and, more specifically, their self-efficacy are of primary importance (Konig et al., 2020; Markova, 2019). The perception of teachers' own self-efficacy and the impact of their new roles during the pandemic on their professional identity formation (Velikova, 2019) may influence their decisionmaking and potential pro-active behavior in conditions of change and ongoing adaptation.

Trainee-teachers were among those who were most severely affected by the closure of schools, a fact which entailed an impossibility to gain hands-on experience in teaching as offered by school-based placements. Given the role which the context of learning has on trainees (see Lofthouse et al., 2020), depriving them from practicing in schools was a major drawback to their preparation. In order to relate what they have learnt to practice, trainees had to rely on their own previous experiences as learners or on reflecting on vicarious experiences such as observing recorded lessons and talking to teacher-trainers or practicing teachers. With the beginning of the pandemic school placements were cancelled or suspended, and even in contexts in which they were carried out as a quick adaptation to the lockdown circumstances, the challenges for the trainee-teachers outweighed the benefits they received (Sepulveda-Escobar \& Morrison, 2020). 
The forced switch to online teaching in schools worldwide, including Bulgaria, was in its nature a transition to synchronous (or simultaneous), rather than asynchronous teaching, which to a lot of teachers meant conducting the same type of lessons and using the same resources with the only difference of teaching online, not in the real classroom. Since synchronous teaching relies on teacher-, rather than student-centered approaches (see Murphy et al., 2011), it was not perceived by teachers as completely different, and, consequently, did not lead to any serious changes in their approaches to teaching. Although this fact eases the adaptation to online teaching, reducing the scope of change to a need to adapt to a new environment rather than to a new way of teaching, research presents evidence that asynchronous learning has advantage over synchronous faceto-face instruction. In fact, according to research, synchronous learning has a small but significant negative effect due to students feeling hurried to respond or hampered by technology breakdowns (see Means, 2013). There are other factors too, which cause difficulties in the transition to online teaching, among which are teacher-student and student-student communication, the extent and nature of reflection, student accountability, and assessment are very different from the face-to-face classroom (Lowes, 2008).

\section{Methodology and research questions}

The data analysed for the purposes of the present study come from three main sources. First, the lesson plans developed by the teacher trainees, second - the oral discussions of the plans between the trainees and the university lecturer responsible for the teaching practice, and third - video clips of online lessons taught by those of the trainees who already worked as teachers at schools. The study involved 52 post-graduate teacher-trainees of an MA programme in Methods in English Language Teaching (the Bulgarian equivalent of MA in TESOL) in a Bulgarian state university. The trainees had to submit two lesson plans for teaching different grades (either those they normally work with at school, or two plans for grades of their choice). 17 trainees submitted short 15minute video clips from online lessons they had taught. Some of the practicing teachers were not allowed to film their lessons due to school-imposed restrictions or technical difficulties.

The modifications in lesson planning were identified by the author of the present article through analysis of lesson plans produced by the trainees after the transition to online teaching in comparison with lesson plans for face-to-face teaching before the pandemic. The nature of the changes and the reasons behind them were discussed with the trainees during online classes at university.

The changes in teaching, including classroom management and use of materials, and were analysed from two perspectives: from the point of view of the observer in interpreting the video recordings and discussions with the 
teachers who submitted the videos, and from the point of view of the teachers through a comparison between their teaching prior to the pandemic and after the transition to online teaching.

The research questions which the present study aims to answer are:

1. Are there any changes in teacher-trainees' lesson planning for online lessons compared to face-to-face lessons, and if there are, what has caused them?

2.Are there any significant changes in the teachers' behavior when teaching online and how these changes, if present, affect teachers' approaches to introducing and practicing key language and skills, their work with instructional materials and their class management?

\section{Analysis and discussion}

The section that follows provides analysis and discussion of the changes following the order set by the research questions and traces the changes in lesson planning and their reflection in teaching the lessons, focusing consecutively on presenting the target language, practicing the four skills, using the teaching materials and aids, and managing online classrooms.

\section{Changes in lesson planning}

Lesson planning is an essential skill which trainees learn in the process of their education. The participants of the present study were first introduced to the concept of planning in the course called Methods in English language teaching. Simultaneously, in a course of lesson observation, they watched and discussed video lessons taught to students of different age and proficiency. Trainees had the chance to compare the observed teachers' lesson plans with the actual procedures in the classroom and then make comments on the relations between the plan and its execution, trying to explain any changes or deviations from the planned activities and procedures. In normal circumstances, by the beginning of their school placement, trainees will have visited schools to observe live lessons, and will have planned and taught one or two lessons to students of different grades. They will have received valuable feedback on their first attempts at teaching by their colleagues and by the university teaching practice supervisor.

In their planning, trainees could use a template of their choice (from those used and discussed during their training), which included the key elements present in any lesson plan. First of all, they had to define the aims of the lesson (in terms of language and skills), including any personal aims usually related to improving some perceived challenges in their own teaching, and the objectives, which are more specific or related to particular aspects in the lesson. Second, trainees had to foresee any things in the lesson which might go wrong and to think 
about possible solutions to the anticipated problems. Next, they had to plan the development of their lesson in terms of its main stages (including the activities or steps within the stages), to describe the procedures, i.e. what the teacher and students will be doing, the estimated time for each stage, and the interaction patterns. The trainees were also encouraged to make notes on the rationale for each stage - stating the reason behind teachers' actions in each stage or activity in the plan. In writing a rationale trainees learn how to justify the logic of the teacher's decision making, and give the whole plan a feeling of structure, logic and coherence.

The observed changes in planning for online lessons fell into several key areas which corresponded to the obligatory elements of the lesson plan. First, the lesson aims in most plans were formulated from the teacher's perspective (what the teacher would do) rather than from the perspective of what students would learn or practice in the lesson. Trainees, especially those who work as teachers, formulated aims which were more realistic in terms of the amount of material to be covered in the lesson. They explained this with the Ministry of Education recommendations, according to which schools were allowed to shorten the lesson by 10 to 20 minutes depending on students' age. It is plausible to assume that the most important factor in setting the aims of a lesson was teachers' familiarity with the students they taught.

In the submitted plans there was an increase in the number of anticipated problems and the possible solutions foreseen by the trainees compared to those for face-to-face teaching. In addition, the problems were more varied in their nature, and involved possible issues with technology, students' behavior online, students' participation in the lesson, classroom language, use of mother tongue, timing of activities, etc. There was also more than one suggestion for solving each of the anticipated problems, and as expected, the practicing teachers, who have already experienced some of the problems, suggested more practical solutions compared to trainees who had no experience of teaching. This could also be explained with the uncertainty and novelty of online teaching and the trainees' efforts to ensure positive teaching and learning experiences.

Planning the stages in a lesson depends on its aims, so any changes in the aims inevitably affect the stages, their number and duration. In the surveyed plans, the introduction was shorter and almost always preceded by attendance check, which is understandable having in mind the reduced duration of classes and the need for formal control of attendance. Homework check was usually planned for, especially with younger learners. In face-to-face classes the teacher can go around the class and see students' notebooks, which is not possible in the online format. Therefore, teachers felt that they should spend time checking homework and responding to any difficulties students might have experienced. The general impression was that, in planning online lessons, trainees tended to follow the 
activities in the online course book more closely, which meant that there were fewer teacher-designed activities. The timing of the stages in the reviewed plans was more flexible, and, in some of the plans, it was not indicated. Some trainees said that they preferred to indicate the minimum number of examples to do in class, and leave the rest for homework. The timing in online lessons was strictly controlled by the teacher, which made both plans and lessons very teacher-centered.

The part of the trainees' plans which depicted the procedures in online lessons contained descriptions of what teachers would do rather than students' actions, which reinforced the impression of teacher-centredness in the plans. The procedures describing online teaching didn't differ significantly from those planned for face-to-face lessons. This might mean that the trainees were not aware of any specific ways in which they can teach and engage students' attention in online classes.

Interaction patterns, which as a rule depend on the nature of the activities, in the plans for online teaching were predominantly whole class and individual work, emphasizing the role of teacher-centered instruction, and relying on teacher nomination of students to answer. There was almost no pair or group work. Some educational platforms provide break-out rooms in which students can do speaking activities in groups, which allows the teacher to listen to students without intervening, and thus increase students' talking time. However, this option is mainly used in higher education or with older learners, and none of the reviewed plans or recorded lessons contained activities done in groups or pairs.

There were no significant changes observed in defining the rationale behind each of the stages in the lesson plans. This might mean that for the trainees the logic of sequencing stages and activities in a lesson did not depend on whether they are taught face-to-face or online.

\section{Features of online teaching}

As expected, the changes in lesson planning were duly reflected in the teaching the lessons, which can easily be seen in the videos submitted together with the plans. A number of changes to the teaching approaches were made by the trainees both consciously and subconsciously, in an attempt to adjust their teaching to the modifications of the online learning environment. This helped to identify some features of online teaching which shed light on the processes of adaptation and adjustment which teachers go through, and the way they affect the nature of their teaching. 


\section{Changes in presenting and practicing language items and skills}

A distinctive feature of online teaching observed in most recordings was teachers' preference for explicit deductive teaching of grammar. Some teachers even referred students to grammar guides or sections in the course books, or used powerpoint presentations containing examples of grammar structures and the rules for their formation and manipulation. There was no contextualization of target language forms or incidental focus on form as defined by Long (1991). A direct consequence of this reduced use of the target language was the teachers' use of translation equivalents to convey the meaning of key lexical and grammatical units. When asked about it in the discussion, they shared their fears that using concept checking questions to check students' understanding, and explaining lexical or grammatical meaning in English would have been too time-consuming, bearing in mind the reduced duration of classes. For presenting vocabulary some teachers used slides with vocabulary items and their definitions in English, and elicited the Bulgarian equivalents from the students. However, this was observed only in the lessons for more advanced learners. With the beginners or younger learners the teachers used mainly translation equivalents and pictures.

Skills development in online lessons did not differ significantly from the usual procedures in live lessons. Some teachers tended to read out the listening material instead of letting students listen to the original recordings, especially when teaching young learners. They justified this with the reduced options for monitoring and control of students' engagement with the task. The same justification was used for another common practice in developing students' reading skills - getting students to read the texts aloud and then giving them time to process the text individually and do the comprehension activities.

As already mentioned in the section related to planning interaction patterns, most of the speaking activities were strictly controlled and teacher-centered. There was more speaking as transaction between teacher and students than speaking as interaction among students themselves. A lot of teachers admitted that the problem of uneven student participation was exacerbated in online teaching. They explained it with students' lack of motivation or with their own difficulties in engaging the learners in communication activities. Some teachers pointed out that the lack of eye contact when teaching large classes reduces the effectiveness of communication.

The development of students' writing skills was probably the most neglected aspect of online teaching. Writing was predominantly used as a means for recording new language items or doing exercises. Writing as an end, i.e. creating texts of different kind, due to mainly time-related considerations, was almost always assigned for homework. Some elements of the product approach, such as discussing the key features of specific types of texts, were used by the teachers 
mainly in the form of input. The occasional oral feedback to students' written assignments was usually provided at the beginning of a lesson, and was focused predominantly on language mistakes.

\section{The use of teaching materials in online lessons}

The observed approaches to online teaching revealed some new tendencies and preferences in using teaching materials. All teachers who submitted video recordings of their lessons relied mainly on the electronic coursebooks and workbooks they used in class before the lockdown. The most widely used additional teaching resources were powerpoint presentations containing a lot of pictures, not all of which exploited appropriately for the purposes of language teaching. In some lessons for young learners there were plenty of visuals which were not necessarily used for elicitation, description or discussion purposes, but for mere decoration or attracting students' attention. As already mentioned, another type of teacher-prepared materials was a sequence of slides or a single slide containing new vocabulary with their translation equivalents which students were asked to re-write before a listening or reading comprehension activity. This approach to introducing vocabulary, which can easily be traced back to the grammar-translation method, in most cases failed to provide adequate contextualization of key language and preempted the comprehension activities which followed.

\section{Modifications in classroom management}

The analysis of the oral discussions with teachers and the recorded video clips revealed some important changes in managing students in online teaching. Most of the trainees admitted that their lessons were much more teacher centered than their own live classes, explaining it with the difficulties in controlling the timing of activities and students' participation in the lesson. The recordings confirmed this impression. Another factor conducive to increased teacher-centeredness was the shortened duration of classes and teachers' perceived fear of insufficient time for covering the planned amount of teaching material.

Another aspect of online teaching which the trainees expressed concerns about was the reduced opportunity for monitoring students' work and the lack of firsthand information about the difficulties which students experienced unless they asked questions or reported problems. As a result, the teacher had to nominate students to provide answers or make contributions or, alternatively, rely on volunteers and thus, work with the pace of the fastest. A way to overcome this was observed in one lesson in the teacher's decision to get students to vote for the correct answers instead of nominating students to answer. 
The review of submitted lesson recordings revealed another common feature of online teaching - increased teacher talking time as a result of lecturing and lengthy explanations. When teachers did not get sufficient feedback on students' understanding, they tended to spend more time explaining and checking understanding. When teaching younger learners online, some of the recorded teachers spoke mostly students' mother tongue instead of the target language. In addition to seeing this is as a more efficient and less time-consuming way of conveying meaning when introducing new language items, teachers used Bulgarian as classroom language too. In the interview they shared that by doing so they felt more in control of the situation, especially when working with younger learners.

\section{Conclusion and implications}

The discussion of the changes in planning and teaching approaches induced by the transition to online teaching allowed us to identify some recurring features, the most important of which was the increased teacher-centredness in both planning and teaching, which often resulted in teacher lecturing and explaining at the expense of students practicing and producing the target language. The lack of monitoring often led to teachers' problems with the timing of activities, especially when students worked on their own. As a result, teachers worked with the pace of the fastest or constantly asked students if they were ready. The other consequence of the transition to online teaching was the perceived need for explicitness and repeated instructions, deductive and overt approaches to presenting key language, the use of translation as a shortcut to meaning, and the lack of appropriate contextualization of language items. A major drawback in developing students' receptive skills was the reduced use or the lack of real listening and reading in which students can process the text on their own. As a result, a lot of the comprehension activities were preempted, and instead of spending time on comprehension, students had to rewrite the correct answers in their notebooks. Another serious limitation was the lack of communicative activities and, in some lesson, the lack of speaking opportunities for most of the students in class. The variety of teaching materials used in face-to-face classrooms was reduced to the electronic course materials already used before the lockdown. The only other resources created by the teachers were slides dealing with grammar or containing new vocabulary. The most prominent features of classroom management can be summarized as excessive use of students' mother tongue and increased error correction irrespective of the task nature. In order to compensate for the insufficient time in class, teachers tended to assign a lot of homework, which, as they themselves admitted, was often left without any feedback to students. 
Looking for solutions to these crisis-induced problems, the changes listed above should be considered in order to redesign and improve online teaching as it will not and should not remain a thing of the past after the pandemic, and the teachers should be ready to implement the learnt lessons in a future hybrid form of education that is more flexible and more student-centered. Back in 2013, Palloff and Pratt pointed out that "the key to success in an online class rests not with the content that is being presented, but with the method by which the course is delivered" (2013, p. 190). The changes in the nature of conceptualizing and implementing teaching which were induced by the Covid-19 pandemic might pave the way to a new teaching and learning philosophy, and it remains to be seen how the initial difficulties caused by the transition to online teaching will give rise to new developments in education.

\section{References}

Cutri, R.M., Mena, J., \& Feinauer Whiting, E. (2020). Faculty readiness for online crisis teaching: transitioning to online teaching during the COVID-19 pandemic. European Journal of Teacher Education, 43(4), 523-541. https:// doi.org/10.1080/02619768.2020.1815702

Downing, J. J., \& Dyment, J. E. (2013). Teacher educators' readiness, preparation and perceptions of preparing pre-service teachers in a fully online environment: An exploratory study. Teacher Educator, 48(2), 96-109.

Dyment, J. E., \& Downing, J. J. (2018). Online Initial Teacher Education Students' Perceptions of Using Web Conferences to Support Professional Conversations. Australian Journal of Teacher Education, 43(4), 68-91.

Garrison, D. R., Anderson, T., \& Archer, W. (2010). The first decade of the community of inquiry framework: A retrospective. Internet and Higher Education, 13 (1-2), 5-9.

König, J., Jäger-Biela, D. J., \& Nina Glutsch, N. (2020): Adapting to online teaching during COVID-19 school closure: teacher education and teacher competence effects among early career teachers in Germany. European Journal of Teacher Education, 43(4), 608-623. https://doi.org/10.1080/02619 768.2020 .1809650

Lofthouse, R., Greenway, C., Davies, P., Davies, D., \& Lundholm, C. (2020). Pre-service Teachers' Conceptions of Their Own Learning: Does Context Make a Difference? Research Papers in Education. doi:10.1080/02671522.20 20.1767181 .

Long,M.(1991).Focusonform:Adesignfeatureinlanguageteachingmethodology. In de Bot, K., Ginsberg, R., \& Kramsch, C. (Eds.), Foreign language research in cross-cultural perspective (pp. 39-52). Amsterdam: Benjamins. 
Lowes, S. (2005). Online teaching and classroom change: The impact of virtual high school on its teachers and their schools. Columbia, New York: Teachers College, Columbia University. Retrieved from http://www.ilt.columbia.edu/ publications/lowes_final.pdf

Markova, Z. (2019). Az-efektivnost v podgotovkata na badeshtite uchiteli po angliyski ezik. Ruse: Avangard print [Аз-ефективност в подготовката на бъдещите учители по английски език. Русе: Авангард принт.] ISBN 978954-337-387-1

Means, B., Toyama, Y., Murphy, R., \& Baki, M. (2013). The effectiveness of online and blended learning: a meta-analysis of the empirical literature. Teachers College record, 115(3), 1-47.

Murphy, E., Rodrigues Manzanares, M., \& Barbour, M. (2011). Synchronous and asynchronous online teaching: Perspectives of Canadian high school distance education teachers. British Journal of Educational Technology, 42 (4), 583-591.

Muthuprasad, T., Aiswarya, A., Aditya, K. S., \& Jha, G. K. (2021). Students' perception and preference for online education in India during Covid-19 pandemic. Social Sciences and Humanities Open, 3(1), 1-11. https://doi. org/10.1016/j.ssaho.2020.100101

Palloff, R. M., \& Pratt, K. (2013). Lessons from the Virtual Classroom. The Realities of Online Teaching. $2^{\text {nd }}$ edition. San Francisco CA: Jossey-Bass, A Wiley imprint.

Roblyer, M., Porter, M., Bielefeldt, T., \& Donaldson, M. (2009). "Teaching online made me a better teacher": Studying the impact of virtual course experiences on teachers' face-to-face practice. Journal of Computing in Teacher Education, 25(4), 121-126.

Scull, J., Phillips, M., Sharma, U., \& Garnier, K. (2020). Innovations in Teacher Education at the Time of COVID19: An Australian Perspective. Journal of Education for Teaching, 46(4), 497-506. doi:10.1080/ 02607476.2020 .1802701 .

Sepulveda-Escobar, P., \& Morrison, A. (2020): Online teaching placement during the COVID-19 pandemic in Chile: challenges and opportunities. European Journal of Teacher Education, 43(4), 587-607. https://doi.org/10.10 80/02619768.2020.1820981

Toffler, A. (1970). Future shock. New York: Random House.

Velikova, S. (2019). Teacher Learning as Becoming: Reflections on Language Teacher Identity. Veliko Tarnovo: IVIS. ISBN 978-619-205-116-7.

Warner, A. G. (2016). Developing a community of Inquiry in a face-toface class: How an online learning framework can enrich traditional classroom practice. Journal of Management Education, 40(4), 432-452. doi: $10.1177 / 1052562916629515$. 